\title{
Pesticide and surfactant mixtures alter sexual differentiation in Japanese Medaka (Oryzias latipes)
}

5

6 Shuying Li ${ }^{\text {a b }}$, Tiantian $\mathrm{Hu}^{\text {a }}$, Luísa Becker Bertotto ${ }^{\text {b, }}$ Yao Jiang a , Wenjun Gui ${ }^{\text {a* }}, 7$

Daniel Schlenk ${ }^{b^{*}}$

$8{ }^{\text {a }}$ Institute of Pesticide and Environmental Toxicology, Zhejiang University, Hangzhou, 9 310058, PR China

$10{ }^{\mathrm{b}}$ Department of Environmental Sciences, University of California, Riverside, CA

$11 \quad 92521$

12

13 Corresponding Authors

14 *Daniel Schlenk

15 Phone: 1- 951-827-2018; fax: 1-951-827-3993; e-mail: dschlenk@ucr.edu

$16 *$ Wenjun Gui

17 Phone/fax: 86-0571-88982220; e-mail: guiwj@zju.edu.cn

18

19 Supplementary information - methods for analytical chemistry $2-4$

20 Supplementary Tables - Tables $\mathrm{S} 1$................................ 5

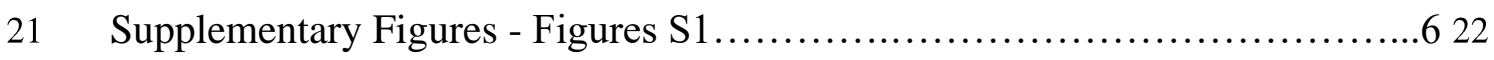

Supplementary Figures - Figures S2 ..............................6

24 Sample Preparation for Chemical Analysis

25 Prior to extraction for chemical analysis, samples were filtered using AP40 glass fiber

26 filters (90 mm diameter, $0.7 \mu \mathrm{m}$ pore size; Millipore) on glass or stainless steel filter

27 holders (Millipore), for 1 or $4 \mathrm{~L}$ samples, respectively. The glass filtration unit was

28 previously baked for $4 \mathrm{~h}$ at $400^{\circ} \mathrm{C}$, and the stainless steel container was rinsed with

29 methanol and deionized water between samples. Extraction typically occurred less than

$3024 \mathrm{~h}$ after filtration. 1L (for diuron) or $4 \mathrm{~L}$ (for 17 $\beta$-Estradiol, bifenthrin and 
31 Alkylphenols and alkylphenol poliethoxylates) of filtered water were spiked with $1 \mathrm{~mL}$

$3250 \mathrm{ng} / \mathrm{mL}$ decachlorobiphenyl (PCB 209) as an extraction surrogate and extracted with

33 90-mm C18 Empore extraction disks (3M) pre-rinsed twice with $30 \mathrm{~mL}$ of methanol 34 and deionized water. After extracting the samples, the disks were dried and stored at 35 $20^{\circ} \mathrm{C}$ until elution with $25 \mathrm{~mL}$ methanol. After elution, the methanol was evaporated to dryness in a vacuum oven, the extracts were reconstituted in $1000 \mu \mathrm{L}$ methanol. Then samples were used for analysis with gas chromatography-mass spectrometry or liquid 38 chromatograph-mass spectrometer

Diuron concentrations were measured by HPLC system (Shimadzu Corporation, Kyoto, Japan), which consisted of one CBM20A communication bus module, two LC20AD41 XR pumps, one DGU20A3R degassing unit, one SIL20AC-XR autosampler, one CTO20AR columnoven, and one SPDM20A photodiodearray (PDA) detector. Fifty microliters of the filtered $(0.22 \mu \mathrm{m})$ water were directly injected into the system, and the compounds were separated by a Shimadzu Shim-Pack XR-ODS column $(2.0 \times$ $100.0 \mathrm{~mm}, 2.2 \mu \mathrm{m}$ particle size, $8 \mathrm{~nm}$ pore size). The PDA detector was set at 200-600 $\mathrm{nm}$ for all analytes, which were quantified at $250 \mathrm{~nm}$. Acetonitrile and water (40:60, $\mathrm{v} / \mathrm{v}$ ) were used as the mobile phase that was isocratically pumped at a flow rate of 0.5 $\mathrm{mL} / \mathrm{min}$. The column oven temperature was set to $40^{\circ} \mathrm{C}$. Chromatogram was monitored during $5 \mathrm{~min}$ and peaks were identified and quantified using LAB Solutions 5.71 software (Shimadzu Corporation). Calculations were based on a calibration curve previously constructed by injecting authentic standards into the HPLC system (10-1000 $\mathrm{ng} / \mathrm{L})$.

The samples were analyzed for bifenthrin by using an Agilent 6890N Gas

Chromatograph with an Agilent 5973 mass
selective

5 Chromatographic separation was performed on an Agilent HP-5 MS capillary

column $(30 \mathrm{~m} \times 0.25 \mathrm{~mm}$ i.d, with $0.25 \mu \mathrm{m}$ film thickness $)$. The injector temperature

was $280^{\circ} \mathrm{C}$ and injection volume was $1.0 \mu \mathrm{L}$ with splitless mode. The gradient temperature program for the GC oven was as follows. Initial temperature $80^{\circ} \mathrm{C}$ (held

for $1 \mathrm{~min}$ ), then increased to $260^{\circ} \mathrm{C}$ at a rate of $30^{\circ} \mathrm{C} / \mathrm{min}$ (held for $2 \mathrm{~min}$ ) and then 60 increased to $300^{\circ} \mathrm{C}$ at a rate of $5^{\circ} \mathrm{C} / \mathrm{min}$. 
61 Analysis of alkylphenol and alkylphenol ethoxylates was carried out using a Waters ${ }^{\odot}$

62 Acquity ultra-performance liquid chromatography tandem mass-spectrometry with

63 electro-spray ionization (UPLC-MS/MS, ESI) equipped with a $100 \times 2.1 \mathrm{~mm}$ Waters

64 BEH C18 column (1.7 $\mu \mathrm{m}$ particle size) and tandem mass spectrometers (Milford, MA).

65 All compounds were quantified using multiple reaction monitoring (MRM). The

66 method for determining alkylphenols (NP and OP) were based on previously optimized

67 methods (Coffin et al., 2018). The method for determining alkylphenol ethoxylates

68 (NP1EO, NP2EO, OP1EO, OP2EO) was based on methods described in (Loyo-Rosales

69 et al., 2003). All samples were analyzed both in positive and negative ESI mode. For

70 both modes, the mobile phases were water (E-pure) with $10 \mathrm{mM}$ ammonium acetate

71 (Optima grade; Fisher, Hampton, NH) and methanol (Optima grade; Fisher, Hampton,

$72 \mathrm{NH}$ ) and the flow rate was $0.4 \mathrm{ml} / \mathrm{min}$. The gradient started with $60 \%$ water and $40 \%$

73 methanol, and starting at 0.5 minutes, the \%methanol increased linearly to $99 \%$ until 2

74 minutes, at which point it was held until 4 minutes, then decreased back to $60 \%$ linearly

75 until 4.5 minutes. The column was then re-equilibrated for 1 minute (total run time 5.5

76 minutes). The column temperature was set to $40{ }^{\circ} \mathrm{C}$, source temperature was $150 \square{ }^{\circ} \mathrm{C}$,

77 extractor voltage was $3.00 \mathrm{~V}$, desolvation gas flow was $800 \mathrm{~L} / \mathrm{Hr}$ and cone gas flow

78 was $50 \mathrm{~L} / \mathrm{Hr}$. For ESI positive mode, the capillary voltage was set to $3.50 \mathrm{kV}$ and the 79 desolvation temperature was $400{ }^{\circ} \mathrm{C}$. For ESI negative mode, the capillary voltage was

80 set to $1.50 \mathrm{kV}$, and the desolvation temperature was $500{ }^{\circ} \mathrm{C}$.

81

82

Parameters used in the UPLC-MS/MS analysis

\begin{tabular}{cccccc}
\hline Abbrev. & Compound & Transition 1 & $\begin{array}{c}\text { T1 CE } \\
(\mathrm{V})\end{array}$ & dwell (s) & $\begin{array}{c}\text { Cone } \\
(\mathrm{V})\end{array}$ \\
\hline NP & 4-n-Nonylphenol & $219.21>106.03$ & -20 & 0.03 & 46 \\
OP & 4-tert-Octylphenol & $205.15>133.0$ & -24 & 0.012 & 40 \\
E2 & 17ß- Estradiol & $271.1>145$ & -15 & 0.020 & 30 \\
OP1EO & Octylphenol monoethyoxylate & $268.0>113.0$ & 10 & 0.015 & 15
\end{tabular}




\begin{tabular}{rrrrrr} 
OP2EO & Octylphenol Diethyoxylate & $312.0>183.0$ & 12 & 0.015 & 20 \\
NP1EO & Nonylphenol monoethyoxylate & $282.4>127.2$ & 10 & 0.015 & 14 \\
NP2EO & Nonylphenol Diethyoxylate & $326.3>183.2$ & 12 & 0.015 & 20 \\
\hline
\end{tabular}
83 
84 Table S1. Sequences of primers for qRT-PCR assay

\begin{tabular}{lll}
\hline Gene & Sequence of the Primer (5'-3') & Sequence of the Primer (3'-5') \\
\hline cyp19a & GCTTTTTGCGCTGCACAGT & GTCAACAGGAACACCCAGGAA \\
$\beta$-actin & TGACGGAGCGTGGCTACTC & TCCTTGATGTCACGGACAATTT \\
\hline
\end{tabular}

85 


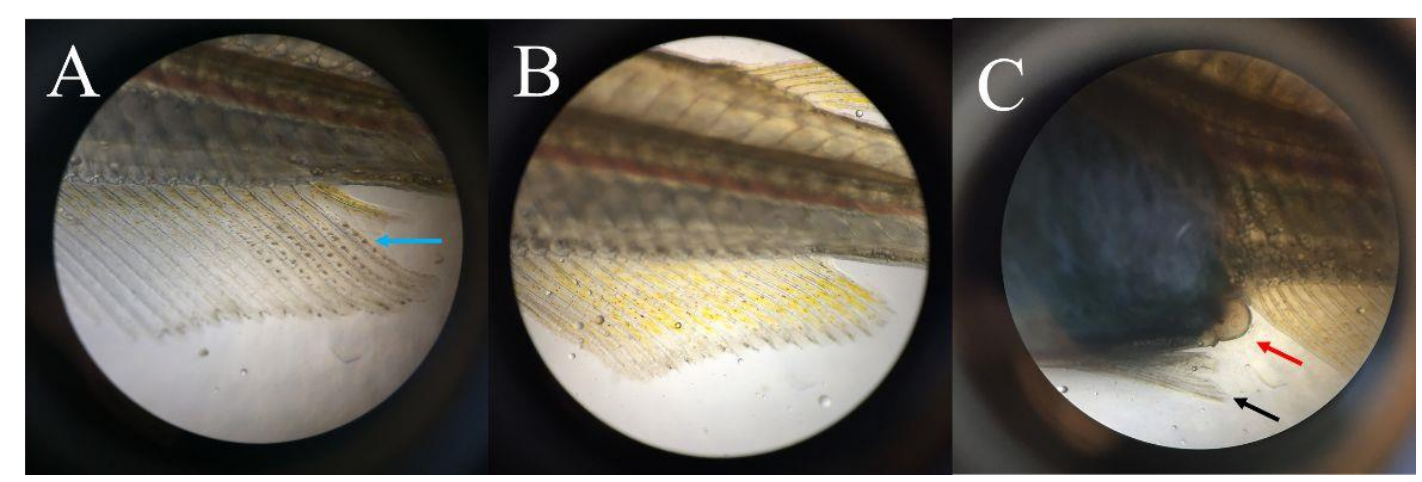

87 Figure S1. Picture of the secondary sex characteristics in Japanese medaka. (A) Anal 88 fin with papillary processes (blue arrow) in DMY-gene present medaka. (B) Anal fin 89 with no papillary processes in DMY-gene absent medaka. (C) Ventral fin (black arrow) 90 and urogenital protuberance (red arrow).

91

92

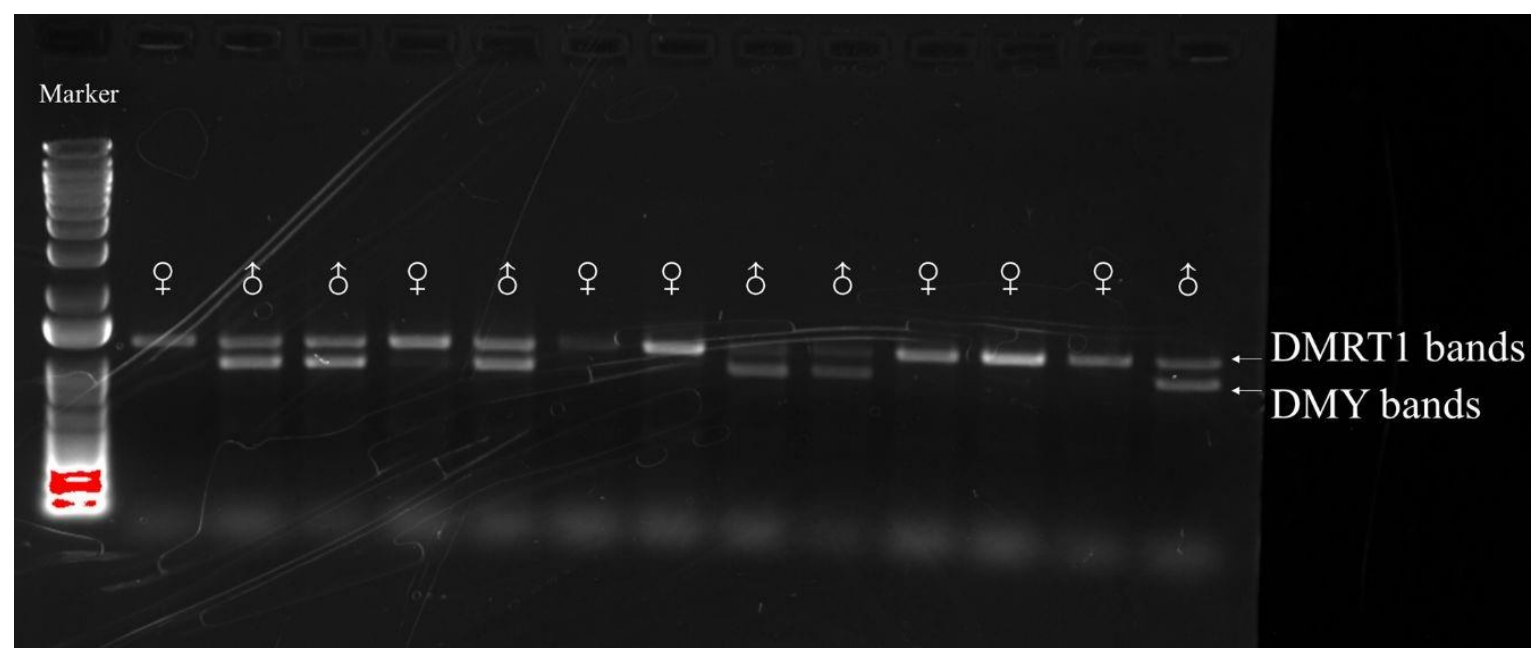

93 Figure S2. Representative gel image for DMY assay of DMRT1 and DMY expression. 